\title{
Avaliação do Índice de Estado Trófico como ferramenta para monitoramento de atividades aquícolas em reservatórios continentais
}

\author{
Emílio Sousa Pinho ${ }^{1}$ \\ Clauber Rosanova ${ }^{2 *}$ \\ Flávia Tavares Matos ${ }^{1}$ \\ Rubens Tomio Honda ${ }^{3}$ \\ Guilherme Wolff Bueno ${ }^{4}$ \\ Alberto Akama ${ }^{5}$ \\ ${ }^{1}$ Embrapa Pesca e Aquicultura do Tocantins, Palmas - TO, Brasil \\ ${ }^{2}$ Instituto Federal do Tocantins, Campus Palmas, Quadra 310 Sul, Lo 5, s/n \\ Plano Diretor Sul, CEP 77021-090, Palmas - TO, Brasil \\ ${ }^{3}$ Faculdade Católica do Tocantins, Palmas - TO, Brasil \\ ${ }^{4}$ Universidade Estadual Paulista, Registro - SP, Brasil \\ ${ }^{5}$ Universidade Federal do Tocantins, Palmas - TO, Brasil \\ * Autor para correspondência \\ clauber@ifto.edu.br
}

Submetido em 15/06/2018

Aceito para publicação em 17/10/2018

\section{Resumo}

A aquicultura é a atividade que mais cresce entre os setores de produção de alimentos, porém, se executada inadequadamente, pode causar a deterioração da qualidade da água. O objetivo do trabalho foi avaliar a utilização do Índice de Estado Trófico (IET) como ferramenta de monitoramento de atividades aquícolas, especificamente do Parque Aquícola Sucupira, área de cultivo de peixes em tanques-rede no reservatório do Lajeado em Palmas/ TO. O monitoramento foi realizado entre janeiro e agosto de 2017, envolvendo a coleta de amostras para análises dos parâmetros de fósforo total e clorofila-a. Paralelamente, houve coleta de dados de temperatura, turbidez, oxigênio dissolvido, condutividade, $\mathrm{pH}$ e sólidos totais dissolvidos. As variáveis limnológicas (temperatura, condutividade, turbidez, oxigênio dissolvido, $\mathrm{pH}$ e sólidos totais dissolvidos), com exceção do fósforo total, apesar das pequenas variações de oxigênio e sólidos totais, estão de acordo com as recomendações da Resolução CONAMA 357/05. Os dados obtidos permitem concluir que a área aquícola apresentou predominância de estado trófico supereutrófico e que o estado trófico do reservatório nas proximidades dos tanques-rede sofre forte influência externa de atividades antrópicas, principalmente no período chuvoso. No período da seca, por não haver a diluição de nutrientes devido à escassez de chuvas, ocorre aumento na concentração de fósforo na água, levando a um estado hipereutrófico. O resultado se deve ao fato de o lago apresentar naturalmente altos índices de fósforo, portanto, não é possível afirmar que a aquicultura seja uma atividade impactante, sendo necessária a adoção de um programa de monitoramento com uma malha amostral mais abrangente em futuros estudos.

Palavras-chave: Aquicultura; Reservatórios; Tanque-rede 


\section{Abstract}

Evaluation of the Trophic State Index as a tool for monitoring activities in continental reservoirs. Aquaculture is the fastest growing activity among food production sectors, however, it may cause environmental impacts if a monitoring plan is not adopted. The objective of the present study was to evaluate the Trophic State Index (TSI) as a tool to monitor aquaculture activity. The study was conducted in Parque Aquícola Sucupira, an area that cultivates fish in a net cage system in Lajeado Reservoir, Palmas, Tocantins. Monitoring was carried out from January to August 2017 and involved sampling to analyze the following water quality parameters: total phosphorus and chlorophyll a. At the same time, other parameters were analyzed in loco: temperature, turbidity, dissolved oxygen, conductivity, $\mathrm{pH}$ and total dissolved solids. The results showed that the concentrations of most of the limnological parameters were under the maximum regulatory limits required in the CONAMA 357/05 legislation. The Trophic State Index (TSI) results showed that the study area was predominantly in a supereutrophic state and that the trophic state of the reservoir around the aquaculture area is strongly influenced by anthropic activities, mainly during the rainy season. In the dry season, since nutrients are not diluted, an increase in phosphorus concentration was recorded, which led to a hypereutrophic state. This result could be because the lake naturally has high levels of phosphorus. Since it was not possible to affirm if aquaculture was the impacting activity, future studies should adopt a monitoring program with a more comprehensive sampling effort.

Key words: Aquaculture; Net cages; Reservoir

\section{Introdução}

A aquicultura é o segmento de produção animal que mais cresce no mundo (FAO, 2016), e esse crescimento tem sido atribuído ao aumento do consumo de proteína animal pela população humana, que em 2017 já ultrapassou 7,6 bilhões de pessoas, e à diminuição crescente dos estoques pesqueiros nos ambientes naturais.

Segundo Bueno et al. (2011), a aquicultura nacional encontra-se em franca expansão, apresentando grande potencial de mercado, ocupação e renda, dada a queda observada na produção do pescado do extrativismo. Entretanto, o grande volume de tanques-rede que vem sendo instalado em reservatórios continentais brasileiros tem trazido impactos na qualidade das águas, resultantes da sobra de ração utilizada nos cultivos e da excreção de nutrientes pelos peixes, causando a eutrofização das águas e a consequente proliferação de algas e macrófitas no corpo hídrico. Esses impactos prejudicam não somente outros usuários de águas, como também outros cultivos em áreas próximas (MATOS et al., 2016).

Nesse contexto, a adoção de planos de manejo e monitoramento é fundamental para minimizar os riscos e otimizar a produção aquícola. Sorbello (2008) afirma que o programa de monitoramento é uma parte integrante e essencial do procedimento que assegura que as alterações ambientais oriundas das atividades de aquicultura estejam em níveis aceitáveis e pré-determinados. Os programas de monitoramento são essenciais, entre outros motivos, para permitir eventuais expansões das atividades produtivas em curso e para garantir que novos desenvolvimentos não impactem negativamente o meio ambiente; por isso o monitoramento deve fornecer informações de base para a tomada de decisões.

Para corpos d'água de classe 2, os parâmetros de qualidade de água devem ser avaliados com base na Resolução Conama no 357, de 17 de março de 2005, que dispõe sobre a classificação e diretrizes ambientais para o enquadramento dos corpos de água superficiais. No entanto, a quantidade de parâmetros é alta, o que praticamente inviabiliza a prática do monitoramento de todos os parâmetros por parte dos produtores.

Nesse contexto, o conhecimento das condições de trofia dos ambientes aquáticos, a partir de limites calculados por indicadores correlacionados ao favorecimento da eutrofização, pode ser uma ferramenta simples e acessível ao produtor na realização de programas de monitoramento. Um exemplo é o cálculo do Índice de Estado Trófico (IET), que tem por finalidade classificar os corpos d'água em diferentes graus de trofia, ou seja, avalia a qualidade da água quanto ao enriquecimento por nutrientes (CETESB, 2009a). 
Lamparelli (2004) propõe para o cálculo da classificação de trofia em reservatórios a inserção dos parâmetros de clorofila-a e fósforo total. O pigmento de clorofila é encontrado em organismos fotossintetizantes como as algas de águas continentais, e a alta concentração desse pigmento é um indicador do crescimento desordenado da população de fitoplâncton presente no ambiente.

O estado trófico de um corpo de água pode ser classificado como oligotrófico, mesotrófico, eutrófico, supereutrófico e hipereutrófico, de acordo com a classificação do estado trófico dos cursos d'água continentais utilizado pela CETESB (2009a) para identificar o grau de poluição ou a condição ambiental da região.

Nesse contexto, o objetivo deste estudo foi avaliar o grau de trofia de um sistema aquícola de produção em tanques-rede, localizado no reservatório de Lajeado, Palmas - TO, denominado Parque Aquícola Sucupira.

\section{Material e Métodos}

\section{Área de estudo}

O estudo foi conduzido na região do Parque Aquícola Sucupira, localizado no reservatório do Lajeado a $15 \mathrm{~km}$ da cidade de Palmas - TO, cujas coordenadas estão descritas na Tabela 1. Os produtores do Parque Aquícola Sucupira exercem a atividade de piscicultura intensiva em sistema de tanques-rede. O reservatório de Lajeado ocupa área de $630 \mathrm{~km}^{2}$ de lâmina de água, representando $0,23 \%$ da área do estado do Tocantins e foi construído basicamente para geração energética, mas também tem sido utilizado para irrigação, pesca, piscicultura, turismo e lazer. A cheia do reservatório ocorreu em 2001 e conta com vazão média de $2.547,99 \mathrm{~m}^{3} / \mathrm{s}$.

\section{Coleta de dados}

No intuito de se mensurar o grau de trofia do ambiente, levando em conta o aporte de nutrientes liberados pela atividade aquícola, foi determinada uma malha amostral de pontos equidistantes, conforme mostra
TABELA 1: Coordenadas Geográficas dos pontos de amostragens, Reservatório de Lajeado, Palmas, Tocantins, Brasil.

\begin{tabular}{ccc}
\hline Ponto & Longitude & Latitude \\
\hline A1 & $-10,086566$ & $-48,373270$ \\
A2 & $-10,086566$ & $-48,371020$ \\
A3 & $-10,086566$ & $-48,368770$ \\
A4 & $-10,088816$ & $-48,373270$ \\
A5 & $-10,088816$ & $-48,371020$ \\
A6 & $-10,088816$ & $-48,368770$ \\
A7 & $-10,091066$ & -48373270 \\
A8 & $-10,091066$ & $-48,371020$ \\
A9 & $-10,091066$ & $-48,368770$ \\
A10 & $-10,094148$ & $-48,372102$ \\
\hline
\end{tabular}

o desenho esquemático da Figura 1. Foram determinados 10 pontos amostrais, abrangendo toda a área de produção do Parque Aquícola Sucupira, sendo que um dos pontos foi localizado fora da área de influência, representando o ponto controle.

Foram realizadas oito campanhas mensais de coleta de água nos pontos determinados, durante o período de janeiro a agosto de 2017. As amostras de água foram coletadas na lâmina superficial $(30 \mathrm{~cm})$, com o auxílio de uma garrafa de Van Dorn. Após a coleta, a água foi armazenada em frascos de polietileno de $1 \mathrm{~L}$, refrigerada a $4^{\circ} \mathrm{C}$ e protegida da luz. Posteriormente, as amostras foram transportadas para o laboratório de Saneamento Ambiental, da Faculdade Católica do Tocantins e do Instituto Federal do Tocantins para análise das concentrações de fósforo total $\left(\mu \mathrm{gL}^{-1}\right)$ e clorofila-a $\left(\mu \mathrm{gL}^{-1}\right)$.

Os parâmetros temperatura $\left({ }^{\circ} \mathrm{C}\right), \mathrm{pH}$, condutividade $\left(\mathrm{MS} . \mathrm{cm}^{-1}\right)$, oxigênio dissolvido $\left(\mathrm{mg} . \mathrm{L}^{-1}\right)$, sólidos totais (mg. $\mathrm{L}^{-1}$ ) e turbidez (NTU) foram analisados in loco mediante o uso de medidor multiparâmetros Horiba U-52G. 
FIGURA 1: Pontos de coleta (A1 a A10) com as coordenadas em WGS-84; Reservatório de Lajeado, Palmas - TO.

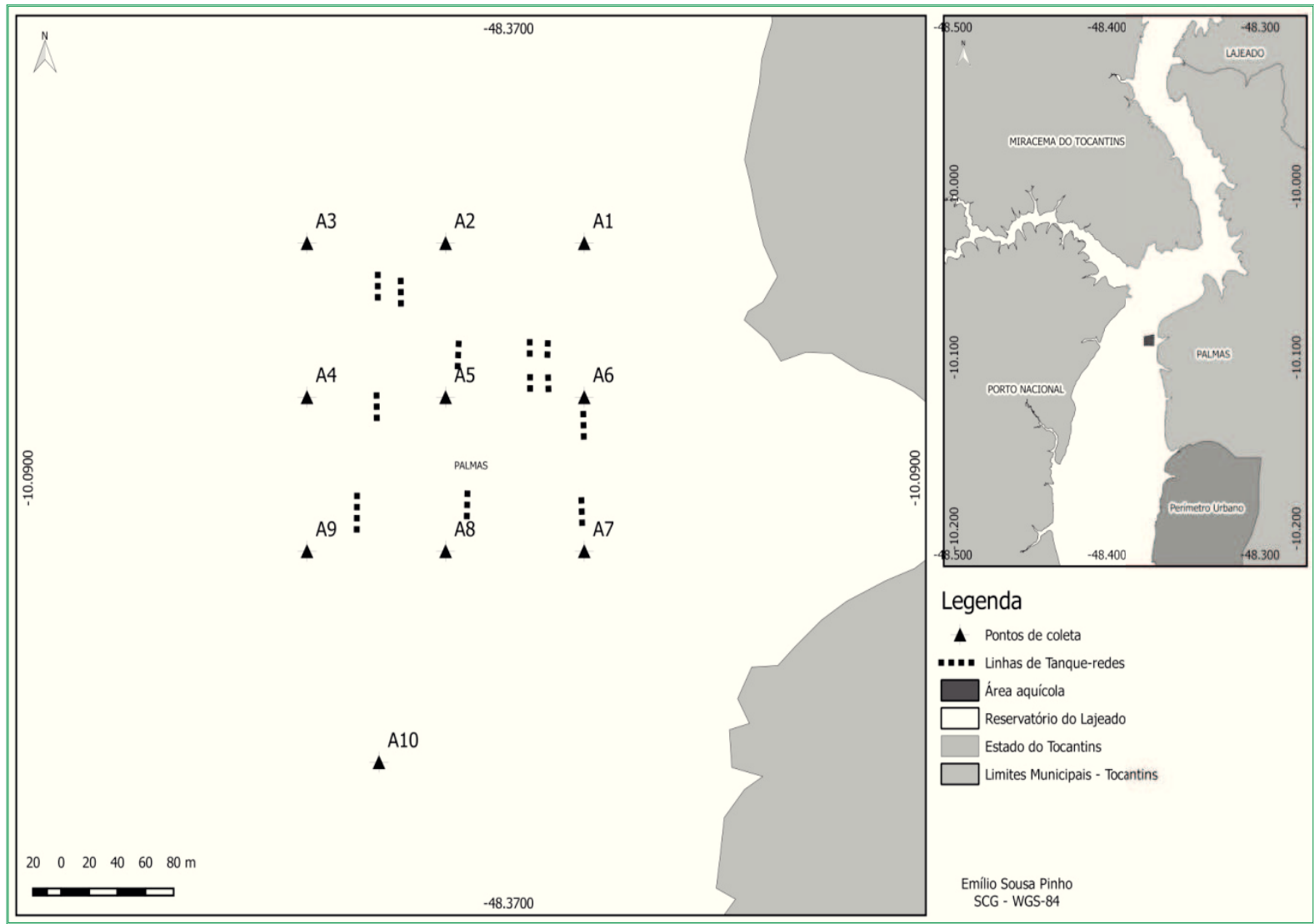

\section{Análises}

\section{Determinação da concentração da clorofila-a}

Para análise da clorofila-a, 0,5 L da amostra de água coletada foi filtrada com auxílio de membranas de fibra de vidro de $0,45 \mu \mathrm{m}$. Posteriormente, a extração das clorofilas foi realizada em meio contendo acetona (90\%) gelada, seguido de maceração com auxílio de um bastão de vidro. O macerado obtido foi centrifugado a $4000 \mathrm{rpm}$ por 10 minutos e armazenado em ambiente refrigerado a $4^{\circ} \mathrm{C}$ por $24 \mathrm{~h}$ para posterior análise. A quantificação da clorofila-a foi obtida a partir da leitura do sobrenadante com o auxílio de espectrofotômetro, utilizando comprimento de ondas de $664 \mathrm{~nm}, 665 \mathrm{~nm}$ e $750 \mathrm{~nm}$, de acordo Standard Methods (1998). Os valores das concentrações de clorofila-a foram obtidos por meio da seguinte equação 1 :

$$
C l a\left(\frac{m g}{m^{3}}\right)=\frac{26,7 \times\left[644_{b}-665_{a}\right] \times V 1}{V 2 \times L}
$$

Onde:

664 : subtração da absorbância obtida em $\lambda=664 \mathrm{~nm}$ e $\lambda=750 \mathrm{~nm}$; 665: subtração da absorbância obtida em $\lambda=665 \mathrm{~nm}$ e $\lambda=750 \mathrm{~nm}$ (densidade óptica após a acidificação);

V1: Volume do extrato de acetona $(\mathrm{mL})$;

V2: Volume filtrado da amostra (L);

L: Caminho ótico da cubeta.

\section{Determinação da concentração do fósforo total}

A quantificação do fósforo total foi realizada por meio da digestão alcalina, utilizando $0,210 \mathrm{mg} . \mathrm{L}^{-1} \mathrm{de}$ Persulfato de Potássio 0,210 mg. $\mathrm{L}^{-1}$ em autoclave a $125^{\circ} \mathrm{C}$ por 25 minutos para determinação de todas as formas de fósforos presentes. Posteriormente, foi feita a quantificação do fósforo total a partir do método 
do ácido ascórbico com concentração 17,6 g.L.- . As leituras das amostras foram feitas em espectrofotômetro a um comprimento de onda $880 \mathrm{~nm}$. A determinação da concentração de fósforo total foi realizada por meio de curva de calibração, obtida pela correlação de concentrações padrões e os resultados de leituras, em que o resultado da equação da reta terá uma soma dos quadrados obtida na curva de calibração para fósforo total (MURPHY; RILEY, 1962; APHA, 1998).

\section{Î́ndice de Estado Trófico (IET)}

O IET foi calculado com base na média aritmética da concentração das variáveis, clorofila-a e fósforo total, analisadas nos 10 pontos amostrais.

Conforme Alves et al. (2012), o Índice do Estado Trófico (IET) é composto por dois outros Índices: Índice de Estado Trófico para o Fósforo e o Índice de Estado Trófico para a clorofila-a, usados por Lamparelli (2004), sendo estabelecidos para ambientes idênticos.

Para a determinação do IET, conforme Lamparelli (2004), utilizam-se as seguintes equações:

$$
\begin{gathered}
\operatorname{IET}_{L}(C l a)=10 \times\left(6-\left(\frac{0,92-0,34(\ln (C l a))}{\ln 2}\right)\right) \\
\operatorname{IET}_{L}(P T)=10 \times\left(6-\left(\frac{1,77-0,42(\ln (P T))}{\ln 2}\right)\right) \\
I E T_{L}=\frac{I E T(P T)+\operatorname{IET}(C l a)}{2}
\end{gathered}
$$

Onde:

$\mathrm{IET}_{\mathrm{L}}$ : Índice de Estado Trófico por Lamparelli (2004);

PT: concentração de fósforo total medida na superfície da água, em $\mu$ g.L -1 $^{-1}$

CL: concentração de clorofila total medida na superfície da água, em $\mu \mathrm{g} . \mathrm{L}^{-1}$

Ln: logaritmo.
Os valores decimais nas fórmulas são constantes delineadas a partir de experimentos de Lamparelli (2004), a partir de correlações logarítmicas.

\section{Resultados}

A Figura 2 demonstra o perfil de variação dos parâmetros de temperatura, $\mathrm{pH}$, condutividade elétrica, turbidez, oxigênio dissolvido e sólidos totais dissolvidos no período de janeiro a agosto de 2017.

\section{Cálcullo do Î́ndice de Estado Trófico}

Para o cálculo do índice de estado trófico, foram determinadas as concentrações dos parâmetros clorofila-a e fósforo total nas estações chuvosa e seca, conforme demonstra a Tabela 2.

TABELA 2: Concentrações médias de clorofila-a ( $\mu \mathrm{gL}-1)$ e fósforo total $(\mu \mathrm{gL}-1)$ na área de estudo, durante as estações chuvosa (de janeiro a abril de 2017) e seca (de maio a agosto de 2017).

\begin{tabular}{ccc}
\hline Parâmetros & $\begin{array}{c}\text { Concentração } \\
\text { Média na estação } \\
\text { chuvosa }\end{array}$ & $\begin{array}{c}\text { Concentração } \\
\text { Média na } \\
\text { estação seca }\end{array}$ \\
\hline janeiro & maio \\
Clorofila-a $\left(\mu \mathrm{g} \cdot \mathrm{L}^{-1}\right)$ & $8,21 \pm 4,78$ & $9,42 \pm 3,96$ \\
Fósforo Total $\left(\mu \mathrm{g} . \mathrm{L}^{-1}\right)$ & $0,14 \pm 0,11$ & $0,35 \pm 0,07$ \\
\hline & fevereiro & junho \\
Clorofila-a $\left(\mu \mathrm{g} \cdot \mathrm{L}^{-1}\right)$ & $6,14 \pm 1,49$ & $4,91 \pm 0,88$ \\
Fósforo Total $\left(\mu \mathrm{g} \cdot \mathrm{L}^{-1}\right)$ & $0,05 \pm 0,04$ & $0,10 \pm 0,01$ \\
\hline & $\mathbf{m a r c ̧ o}$ & julho \\
Clorofila-a $\left(\mu \mathrm{g} \cdot \mathrm{L}^{-1}\right)$ & $7,85 \pm 4,55$ & $2,60 \pm 0,81$ \\
Fósforo Total $\left(\mu \mathrm{g} \cdot \mathrm{L}^{-1}\right)$ & $0,10 \pm 0,03$ & $0,41 \pm 0,05$ \\
\hline & $\mathbf{a b r i l}$ & agosto \\
Clorofila-a $\left(\mu \mathrm{g} \cdot \mathrm{L}^{-1}\right)$ & $1,28 \pm 0,62$ & $9,71 \pm 1,38$ \\
Fósforo Total $\left(\mu \mathrm{g} \cdot \mathrm{L}^{-1}\right)$ & $0,09 \pm 0,07$ & $0,35 \pm 0,06$ \\
\hline
\end{tabular}

A partir dos dados apresentados na Tabelas 2, foram calculados os Índices de Estado Trófico segundo Lamparelli (2004), no período de janeiro a agosto de 2017, conforme é demonstrado na Tabela 3. 
FIGURA 2: Resultados dos parâmetros de temperatura (a), turbidez (b), Oxigênio Dissolvido - OD (c), Condutividade (d), pH (f) e Sólidos Totais Dissolvidos - TDS (g), obtidos na área de produção de pescado Sucupira, no reservatório de Lajeado (período de janeiro a agosto de 2017).

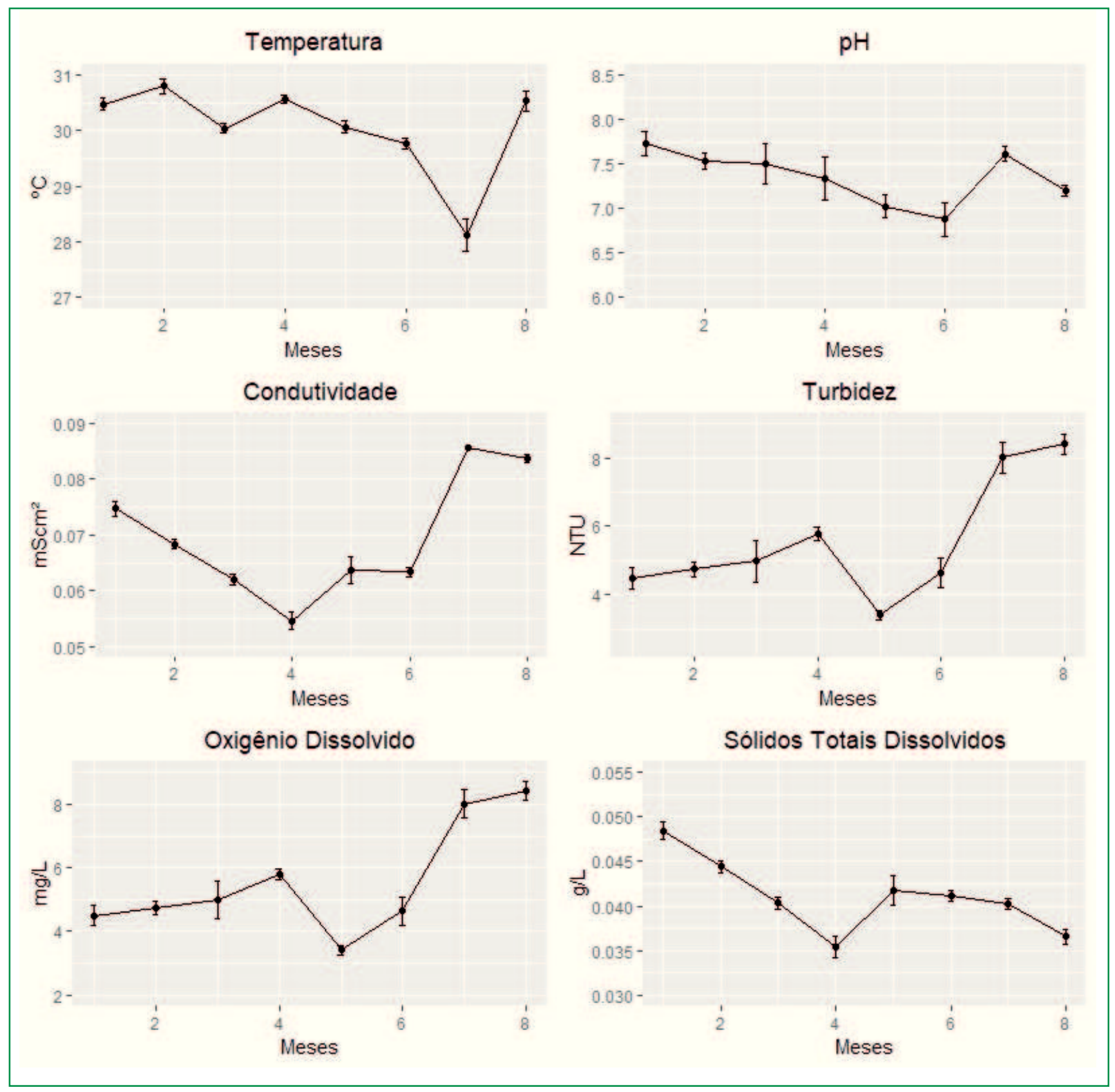


TABELA 3: Índice de estado trófico e grau de trofia na área de estudo no período de janeiro a agosto de 2017.

\begin{tabular}{|c|c|c|c|c|c|c|c|c|}
\hline Ponto & Janeiro & \multicolumn{1}{c}{ Fevereiro } & Março & \multicolumn{1}{c}{ Abril } & \multicolumn{1}{c|}{ Maio } & Junho & Julho & Agosto \\
\hline 1 & 64 & 64 & 65 & 56 & 64 & 64 & 69 & 68 \\
\hline 2 & 65 & 62 & 66 & 49 & 66 & 66 & 68 & 70 \\
\hline 3 & 66 & 63 & 67 & 58 & 65 & 65 & 67 & 70 \\
\hline 4 & 67 & 63 & 65 & 49 & 64 & 64 & 68 & 71 \\
\hline 5 & 63 & 63 & 68 & 54 & 65 & 65 & 66 & 70 \\
\hline 6 & 62 & 64 & 63 & 53 & 64 & 64 & 66 & 70 \\
\hline 7 & 63 & 64 & 61 & 51 & 64 & 64 & 66 & 70 \\
\hline 8 & 69 & 64 & 68 & 53 & 64 & 64 & 67 & 69 \\
\hline 9 & 73 & 62 & 65 & 36 & 65 & 65 & 66 & 70 \\
\hline Média & 66 & 63 & 65 & 51 & 64 & 64 & 67 & 70 \\
\hline
\end{tabular}

\begin{tabular}{|l|}
\hline ultraoligotrófico \\
\hline oligotrófico \\
\hline mesotrófico \\
\hline eutrófico \\
\hline supereutrófico \\
\hline hipereutrófico \\
\hline
\end{tabular}

Para facilitar a visualização, os dados foram espacializados e mapas foram produzidos com o auxílio do software Quantum Gis 2.18, a partir da técnica de interpolação de pontos IDW (Inverse Distance Weighting) (Figuras 3 e 4).
Com relação ao ponto controle, os dados de clorofila-a, fósforo total e a determinação do índice de estado trófico foram organizados separadamente, conforme é demonstrado na Tabela 5.

FIGURA 3: Perfil do estado trófico na área de estudo entre os meses de janeiro e abril de 2017 (A, B, C e D).

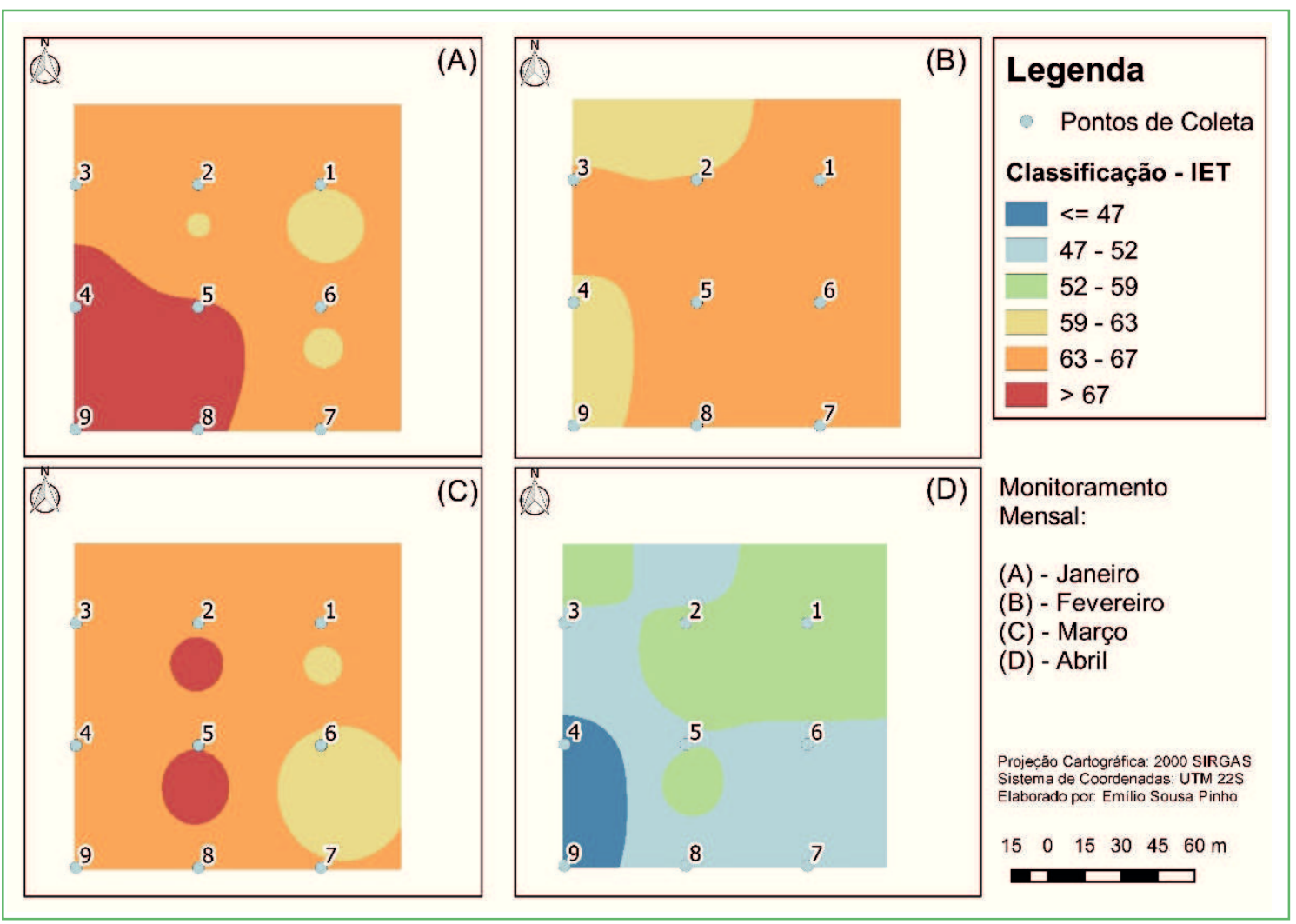


FIGURA 4: Perfil do estado trófico na área de estudo entre os meses de maio e agosto de 2017 (E, F, G e H).

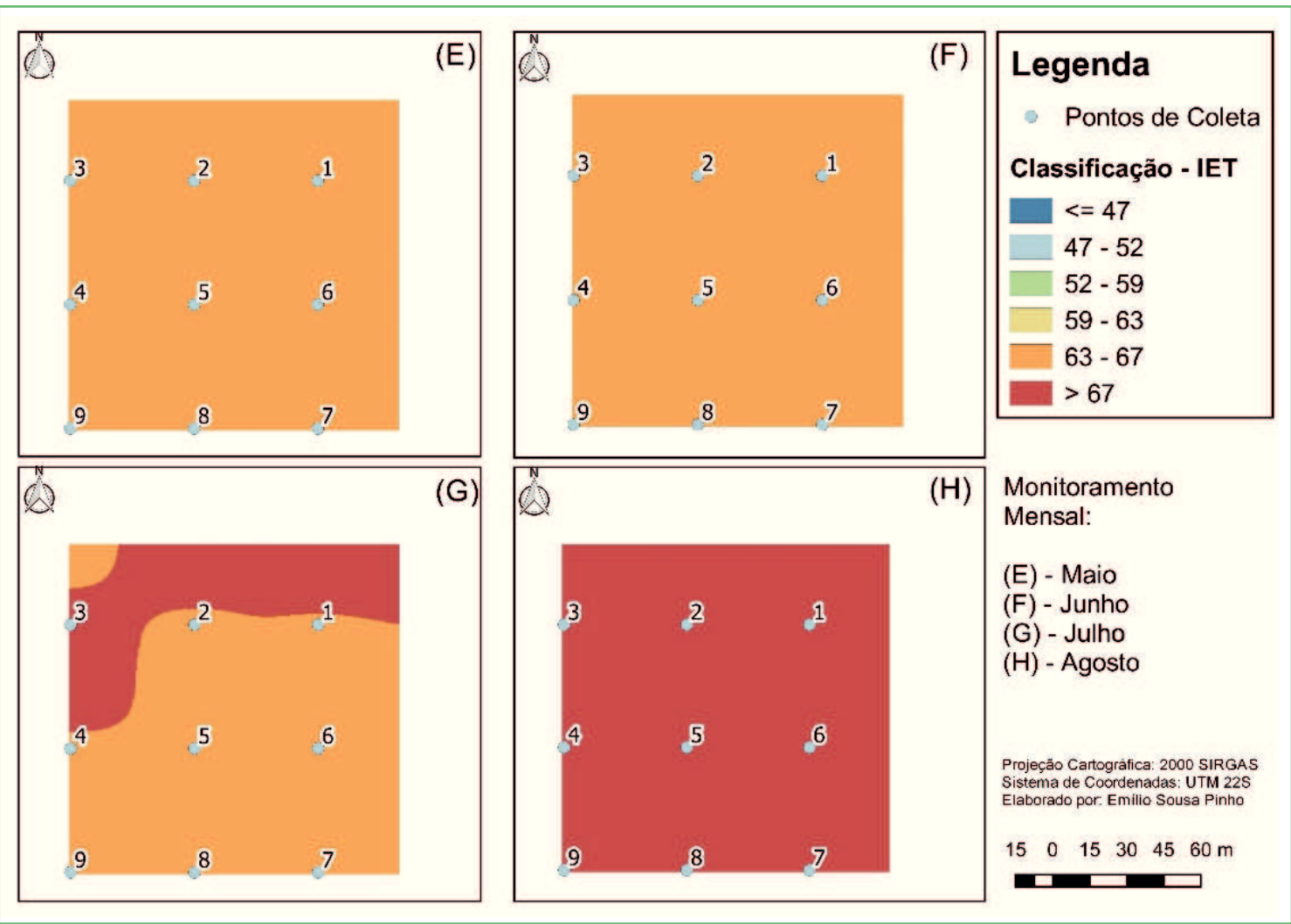

TABELA 5: Concentrações de clorofila-a $\left(\mu \mathrm{g} . \mathrm{L}^{-1}\right)$, fósforo total $\left(\mu \mathrm{g} . \mathrm{L}^{-1}\right)$ e o índice de Estado Trófico (IET) no ponto controle (A10) durante o período de janeiro a agosto de 2017.

\begin{tabular}{lccc}
\hline \multicolumn{1}{c}{ Meses } & Clorofila-a & Fósforo total & IET \\
\hline Janeiro & 10,54 & 0,24 & 53 \\
Fevereiro & 6,62 & 0,06 & 48 \\
Março & 0,53 & 0,06 & 42 \\
Abril & 0,53 & 0,01 & 37 \\
Maio & 4,50 & 0,09 & 64 \\
Junho & 4,50 & 0,09 & 64 \\
Julho & 3,10 & 0,42 & 67 \\
Agosto & 9,70 & 0,40 & 70 \\
\hline
\end{tabular}

\section{Discussão}

Considerando os parâmetros de qualidade de água, durante o período estudado, durante a estação seca, a temperatura média da água foi de $29,62 \pm 0,95^{\circ} \mathrm{C}$, e, na estação chuvosa, de $30,46 \pm 0,32^{\circ} \mathrm{C}$. De acordo com Kubtiza (2003), temperaturas da água entre $26^{\circ} \mathrm{C}$ a $30^{\circ} \mathrm{C}$ correspondem a valores ótimos para o cultivo de peixes. Segundo Marques (2006), no reservatório da Usina Hidrelétrica do Lajeado ocorrem variações de temperaturas entre $25^{\circ} \mathrm{C}$ e $31,70^{\circ} \mathrm{C}$.

Com relação à condutividade elétrica, os valores médios obtidos na estação seca foram de 0,07 \pm $0,01 \mathrm{mS} / \mathrm{cm}$ e nas águas de $0,0545 \pm 2,403 \mathrm{mS} / \mathrm{cm}$, resultados semelhantes aos observados por Peixoto (2007) em estudos na UHE Lajeado. A Resolução CONAMA 357/2005 não determina limites de tolerância específicos para cada parâmetro, porém, a CETESB (2009b) aponta que valores para condutividade elétrica acima de $0,100 \mathrm{mS} / \mathrm{cm}$ indicam a possibilidade de entrada de esgoto no ambiente.

Durante todo o período estudado, os parâmetros de pH e turbidez apresentaram resultados médios dentro dos limites exigidos pela Resolução CONAMA no 357/05 pH 6,0-9,0 e turbidez menor e igual a $100 \mathrm{NTU}$ - para corpos d'água de classe 2 , sendo 7,51 $\pm 0,163$ e 5,00 \pm 
0,555 NTU, respectivamente. Peixoto (2007) observou, em estudos realizados na UHE Lajeado, valores de $\mathrm{pH}$ na faixa de 7,6, variando de ligeiramente alcalino a neutro, o que, segundo Vinatea-Arana (1997), pode ser considerado dentro da faixa de $\mathrm{pH}$ adequada para produção de pescado, a qual varia de 6,5 a 9,0 , sendo que valores de 4,0 e 11,0 (ácido e básico) são letais para vida aquática.

Os valores de oxigênio dissolvido e sólidos totais dissolvidos (STD) em alguns pontos apresentaram resultados fora do limite da Resolução CONAMA 357 na estação seca (meses de maio e junho), conforme o enquadramento de classe 2: oxigênio dissolvido menor ou igual a $5 \mathrm{mgO}_{2} \cdot \mathrm{L}^{-1}$ e concentração máxima de STD de $0,0500 \mathrm{~g} \cdot \mathrm{L}^{-1}$. Na época das águas, apenas os pontos A 5 e A 2 apresentaram valores fora da CONAMA, sendo 4,250 mgO2.L $\mathrm{L}^{-1}$ e 0,0510 g.L. $\mathrm{L}^{1}$ de STD, respectivamente, no decorrer do monitoramento.

Marques (2006) e Peixoto (2007), em estudos na UHE Lajeado, observaram valores diferentes de oxigênio dissolvido para a estação seca, com concentração desse gás variando entre $6,74 \mathrm{mg} . \mathrm{L}^{-1} \mathrm{e} 8,60 \mathrm{mg} \cdot \mathrm{L}^{-1}$. De acordo com Prado (1999), a concentração de oxigênio dissolvido em um corpo hídrico pode ser usada para a determinação da qualidade da água. Quanto mais reduzida for a concentração de oxigênio dissolvido, mais poluído o curso d'água se encontra, influenciando diretamente na biodiversidade aquática. Os valores abaixo (4,25 $\left.\mathrm{mgO}_{2} \cdot \mathrm{L}^{-1}\right)$ do limite tolerado da concentração de oxigênio dissolvido no reservatório de Lajeado podem estar relacionados ao consumo de oxigênio pela degradação excessiva de matéria orgânica ou à forte influência dos processos pluviométricos. Já o excesso de sólidos na água, atribuído ao aumento da concentração dos sólidos totais dissolvidos, uma vez que nos períodos chuvosos há o escoamento de material superficial do solo para o reservatório, pode afetar a comunidade aquática, alterando as condições de luminosidade e interferindo no metabolismo dos seres autotróficos (BUZELLI; CUNHA-SANTINO, 2013).

A concentração média de clorofila-a encontrada nos pontos de amostragem foi de $6,2 \mu \mathrm{g} . \mathrm{L}^{-1}$, permanecendo dentro do valor tolerado pela Resolução do CONAMA 357/05, (até $30 \mu \mathrm{g} . \mathrm{L}^{-1}$ ), para corpo hídrico enquadrado na classe 2. O trabalho de Marques (2006) apontou médias próximas a 5,5 $\mu \mathrm{gCl}-\mathrm{a} . \mathrm{L}^{-1}$ no período das chuvas na UHE Lajeado, enquanto Pereira (2002) observou concentrações de $12,78 \mu \mathrm{gCl}-\mathrm{a} . \mathrm{L}^{-1}$ na fase de enchimento do reservatório.

Segundo Maia et al. (2015), o aumento das concentrações de clorofila-a em reservatórios está relacionado à proliferação de cianobactérias, as quais passam a ser dominantes nesses reservatórios. A concentração da clorofila "a" é utilizada para determinar a biomassa fitoplanctônica (ESTEVES, 1998; GREGOR; MARŠÁLEK, 2004), que, por sua vez, é uma das variáveis utilizadas como indicadora quanto à caracterização do estado trófico de ambientes aquáticos (ESTEVES, 1998). No Reservatório do Lajeado, apesar das altas concentrações de fósforo encontradas, o nutriente encontra-se indisponível para as plantas, fazendo com que não seja evidenciado um crescimento acentuado de algas no local, nem o consequente aumento nas concentrações de clorofila "a".

Com relação ao fósforo total, as concentrações médias encontradas na área de influência do parque aquícola Sucupira se apresentaram acima do permitido na Resolução no 357/05, para ambientes lênticos de água doce, classe 2 (até $0,030 \mathrm{mg} / \mathrm{L}$ ), sendo de $0,301 \mathrm{mg} . \mathrm{L}^{-1}$. Peixoto (2007) calculou a concentração máxima de fósforo afluente admissível por ano para manter o ambiente do reservatório da UHE Lajeado mesotrófico e concluiu que haveria necessidade de reduzir a carga afluente de fósforo de $31.225 \mathrm{kgp} . a n o^{-1}$ para $3.148 \mathrm{kgp}$. $\mathrm{ano}^{-1}$, ou seja, uma redução de $28,07 \mathrm{kgp} . \mathrm{ano}^{-1}$. Na maioria das águas continentais, o fósforo é o principal fator limitante de sua produtividade (ESTEVES, 1998; BUZELLI; CUNHA SANTINO, 2013). Segundo Esteves (1998), esse fato se deve à participação desse elemento em processos fundamentais do metabolismo dos seres vivos, tais como: armazenamento de energia e estruturação da membrana celular. Por isso, tem sido apontado como o principal responsável pela eutrofização artificial desses ecossistemas, pois sua presença, mesmo em pequenas quantidades, causa a proliferação de algas, diminuição de oxigênio e deterioração da qualidade da água, de forma geral. 
De maneira geral, os Índices de Estado Trófico obtidos ao longo do período experimental apresentaramse de forma distinta nas duas estações observadas (Figuras 3 e 4). Na estação chuvosa, durante o mês de janeiro em particular, quando houve um índice de precipitação em torno de $250 \mathrm{~mm}$, os pontos A4, A5, A9 e A8, localizados da área de criação de peixes, apresentaram índices hipereutróficos $(>67)$, e os pontos A1, A2, A3, A6 e A7 apresentaram índices entre supereutrófico (63-67) e eutrófico (59-63) com predominância de supereutrófico. Em fevereiro, período que apresentou leve baixa no índice pluviométrico, em torno de $200 \mathrm{~mm}$, o índice do estado trófico predominante foi o supereutrófico com medidas pontuais de eutrófico nos pontos A2, A3, A4 e A9. Em março, o índice pluviométrico foi em torno de $160 \mathrm{~mm}$ e o índice do estado trófico predominante na área foi o supereutrófico com medidas pontuais e hipereutrófico (A2 e A5) e eutrófico (A1, A6 e A7).

Em abril, período de menor índice pluviométrico observado no período (em torno de $80 \mathrm{~mm}$ ), o índice do estado trófico sofreu melhora, apresentando faixas entre mesotrófico (52-59), nos pontos A1, A2 e A5, oligotrófico (47-52), nos pontos A6, A7, A8 e A3, e ultraoligotrófico $(\leq 47)$, nos pontos A4 e A9. No entanto, houve predominância de grau de trofia oligotrófico $(47<$ IET $\leq 52)$, sendo possível que esse índice se confirme nos períodos de baixo índice pluviométrico, indicando forte influência da chuva no estado trófico do lago.

As médias dos índices de estado trófico da área de influência do Parque Aquícola Sucupira (LAMPARELLI, 2004) obtidas durante os meses de janeiro, fevereiro e março apresentaram grau de trofia classificado como supereutrófico $(63<$ IET $\leq 67)$ na maioria dos pontos amostrados. Devido às condições climáticas do período, não foi possível identificar se as altas concentrações de fósforo obtidas foram decorrentes dos altos índices pluviométricos registrados ou da atividade de piscicultura.

No período de maio e junho, quando foram registrados índices pluviométricos abaixo de $20 \mathrm{~mm}$, todos os pontos localizados na área de influência do Parque Aquícola Sucupira apresentaram índices de estado trófico classificados como eutróficos.
Nos meses de julho e agosto, quando não houve registro de chuva, o índice do estado trófico predominante na área durante o mês de julho foi classificado como eutrófico, com alguns pontos classificados como hipereutrófico. Já em agosto, todos os pontos foram classificados como hipereutróficos.

Da mesma forma que no período seco, o grau de trofia médio obtido na estação chuvosa foi classificado como supereutrófico $(63<$ IET $\leq 67)$ na maioria dos pontos amostrados. Devido à grande influência de atividades antrópicas e à área de pescado ser a jusante da zona de mistura da estação de tratamento de efluente, fica difícil diferenciar efeito antrópico e da atividade da piscicultura sobre o estado trófico da área em estudo.

Pena et al. (2004) realizaram campanhas de monitoramento em 16 pontos amostrais ao longo desse reservatório, durante os anos de 2002 e 2003, onde foram quantificados os parâmetros de transparência, clorofila-a e fósforo total. Os autores observaram que o reservatório da UHE Lajeado apresentou características mesotróficas a partir do cálculo de estado trófico pelo método de Toledo (1990), durante todo o período de estudo e sugeriram que as oscilações nos valores do cálculo de IET de transparência pudessem estar relacionadas à interferência de sólidos totais, que implicam na condição do grau de trofia do ambiente.

Mallasen et al. (2012) avaliaram a condição da qualidade da água em um sistema de piscicultura em tanques-rede no Reservatório de Ilha Solteira São Paulo e concluíram que a produção de peixes na região provoca baixo impacto no ecossistema aquático. O reservatório demonstrou ser eficiente na capacidade de assimilação da carga de nutrientes proveniente de produção de pescado.

Outro estudo a respeito desse tema foi realizado no reservatório de Tucuruí (PA), que simulou a produção de peixe em gaiolas e avaliou os impactos dessa atividade na qualidade da água. Os resultados desse trabalho indicaram aumento de $30 \%$ da carga de fósforo no local do cultivo, entre 2007 e 2011, sugerindo ambiente hipertrófico (DEUS et al., 2013).

De maneira geral, as variáveis limnológicas (temperatura, condutividade, turbidez, oxigênio dissolvido, $\mathrm{pH}$ e sólidos totais dissolvidos), com exceção 
do fósforo total, apesar das pequenas variações de oxigênio e sólidos totais, estão de acordo com os padrões recomendados pela Resolução CONAMA 357/05.

Os dados obtidos permitem concluir que a área aquícola apresentou predominância de estado trófico supereutrófico e que o estado trófico do lago nas proximidades dos tanques-rede sofre forte influência externa de atividades antrópicas, principalmente no período chuvoso. No período da seca, pelo fato de não haver a diluição de nutrientes devido à escassez de chuvas, ocorre aumento considerável na concentração de fósforo na água, levando a um estado hipereutrófico. Contudo, no ponto controle (A10), localizado à montante do cultivo com relação à corrente predominante (sentido norte), o Índice de Estado Trófico se apresentou de forma distinta: no período chuvoso (de janeiro a abril), apresentou-se nas classes de ultraoligotrófico, oligotrófico e mesotrófico, provavelmente devido ao fato de estar localizado em uma área com maior circulação de água, além de ter apresentado aumento na diluição de nutrientes devido aos altos índices pluviométricos registrados no período. Entretanto, no período da seca (maio a agosto), assim como ocorreu com os outros pontos, o índice também se apresentou alto no ponto controle (A10), nas classes de eutrófico e hipereutrófico, indicando que a aquicultura não é uma atividade impactante e que o lago apresenta naturalmente altos índices de fósforo, principalmente na seca.

Os efeitos da atividade são difíceis de serem previstos em longo prazo, bem como o comportamento do reservatório mediante aumento da produção de peixes em tanques-rede, por isso, é fundamental que seja executado um programa de monitoramento constante da qualidade de água.

\section{Agradecimentos}

À Universidade Federal do Tocantins, por meio do seu Programa de Pós-Graduação em Ciências do Ambiente, à Faculdade Católica do Tocantins (Laboratório de Saneamento Ambiental) e ao Instituto de Educação Ciência e Tecnologia do Tocantins, Campus Palmas.

\section{Referências}

ALVES, R. C. P.; BACCARIN, A. E.; LEONARDO, A. F. G. Efeito da produção de peixes em tanques-rede sobre a sedimentação no Córrego do Arribada (baixo Tietê - SP). In: SIMPÓSIO: ECOLOGIA DE RESERVATÓRIOS - IMPACTOS POTENCIAIS, AÇÕES DE MANEJO E SISTEMAS EM CASCATA. 2012, Avaré, 2012. $71 \mathrm{p}$.

APHA - AMERICAN PUBLIC HEALTH ASSOCIATION. Standard methods for the examination of water and wastewater. 20. ed. Washington: APHA, 1998.

BUENO, G. W.; MATOS, F. T. de; CANZI, C.; OSTRENSKY, A.; SAMPAIO, M. B.; BARONE, R. S. C.; ROUBACH, R. A capacidade de suporte: produção de peixes cultivados em reservatórios: bases conceituais (Parte I). Panorama da Aqüicultura, Rio de Janeiro, n. 126 , p. 48-63, 2011.

BUZELLI, G. M.; CUNHA-SANTINO, M. B. Análise e diagnóstico da qualidade da água e estado trófico do reservatório de Barra Bonita (SP). Revista Ambiente \& Água, Taubaté, v. 8 , n. 1, p. 186-205, 2013.

CETESB - COMPANHIA DE TECNOLOGIA E SANEAMENTO AMBIENTAL. Relatório de qualidade das águas interiores do estado de São Paulo 2008/CETESB. Vol. 1. São Paulo: Secretaria de Estado do Meio Ambiente, 2009a. 531 p.

CETESB - COMPANHIA AMBIENTAL DO ESTADO DE SÃO PAULO. Variáveis de qualidade de água. São Paulo, 2009b. Disponível em: <http://www.cetesb.sp.gov.br/Agua/rios/variaveis. asp\#transparencia $>$. Acesso em: 20 out. 2016.

DEUS, R.; BRITO, D.; MATEUS, M.; KENOV, I.; FORNARO, A.; NEVES, R.; ALVES, C. N. Impact evaluation of a pisciculture in the Tucuruí reservoir (Pará, Brazil) using a two-dimensional water quality model. Journal of Hydrology, Amsterdam, v. 487, p. 1-12, 2013.

ESTEVES, F. A. Fundamentos em limnologia. 2. ed. Rio de Janeiro: Interciência/FINEP, 1998. 602 p.

FAO - FOOD AND AGRICULTURE ORGANIZATION. The state of world fisheries and aquaculture 2016. Contributing to food security and nutrition for all. Roma: FAO, 2016. 200 p.

GREGOR, J.; MARŠÁLEK, B. Freshwater phytoplankton quantification by chlorophyll a: a comparative study of in vitro, in vivo and in situ methods. Water Research, London, v. 38, n. 3, p. 517-522, 2004

KUBITZA, F. Qualidade da água no cultivo de peixes e camarões. 1 ed. Jundiaí: Editora Kubitza. 2003. 229 p.

LAMPARELLI, M. C. Graus de trofia em corpos d'gua do estado de São Paulo: avaliação dos métodos de monitoramento. 2004. 207 f. Tese (Doutorado em Ciências) - Universidade de São Paulo, São Paulo. 2004

MALLASEN, M.; CARMO, C. F.; TUCCI, A.; BARROS, H. P.; ROJAS, N. E. T.; FONSECA, F. S.; YAMASHITA, E. Y. Qualidade da água em sistema de piscicultura em tanques-rede no reservatório de Ilha Solteira, SP. Boletim do Instituto de Pesca, São Paulo, v. 38, n. 1, p. 15-30, 2012.

MARQUES, A. K. Análise da diversidade fitoplanctônica no reservatório da Usina Hidroelétrica Luis Eduardo Magalhães, no médio Tocantins - TO: estrutura da comunidade, flutuações temporais e espaciais. 2006. 158 f. Dissertação (Mestrado em 
Ciências do Ambiente) - Universidade Federal do Tocantins, Palmas. 2006.

MATOS, F. T.; WEBBER, D. C.; FONTOURA, A. C.; PINHO, E.; ROUBACH, R.; BUENO, G. W.; FLORENCIO, D.; BARROS, D. J. Monitoramento de qualidade de água das atividades aquícolas em reservatórios continentais brasileiros. Palmas: Embrapa Pesca e Aquicultura, (Séries Embrapa), 2016. 66 p.

MURPHY, J.; RILEY, J. P. A modified single solution method for the determination of phosphate in natural water. Analytica Chimica Acta, Amsterdam, v. 27, p. 31-36, 1962.

PEIXOTO, R. H. P. B. Efeitos da implantação do reservatório da Usina Hidrelétrica Luis Eduardo Magalhães sobre a qualidade da água do rio Tocantins (TO, Brasil). 2007. 222 f. Tese (Doutorado em Engenharia Ambiental) - Universidade Federal do Rio de Janeiro, Rio de Janeiro. 2007.

PENA, L.; FERREIRA, C.; ALMEIDA, M. Comportamento dos índices do estado trófico de Carlson (IET) e modificado (IETM) no reservatório da UHE Luís Eduardo Magalhães. TocantinsBrasil. In: CONGRESO INTERAMERICANO DE INGENIERÍA SANITARIA Y AMBIENTAL, 29, 2004, San Juan. Anales... San Juan: AIDIS, 2004. p. 1-6.

PEREIRA, V. L. R. A limnologia e o gerenciamento integrado do reservatório da Usina Hidrelétrica Luis Eduardo Magalhães - UHE Lajeado, Tocantins. 2002. 284 f. Tese (Doutorado em Ciências da Engenharia Ambiental) - Universidade de São Paulo, São Carlos, 2002.
PEZZATO, L. E.; BARROS, M. M.; FRACALOSSI, D. M. Nutrição de peixes. In: CYRINO, J. E. P.; URBINATI, E. C.; FRACALOSSI, D. M. (Ed.). Tópicos especiais em piscicultura de água doce tropical intensiva. São Paulo: Tecart, 2004. p. 75-169.

PRADO, R. B. Influência do uso e ocupação do solo na qualidade da água: estudo no médio rio Pardo - SP (período de 1985 a 1997). 1999. 209 f. Dissertação (Mestrado em Ciências da Engenharia Ambiental) - Universidade de São Paulo, São Carlos. 1999.

MAIA, A. A. D; CARVAlHO, S. L.; CARVAlHO, F. T. Comparação de dois índices de determinação do grau de trofia nas águas do Baixo Rio São José dos Dourados, São Paulo, Brasil. Engenharia Sanitaria e Ambiental, Rio de Janeiro, v. 20, n. 4, p. 613-622, 2015.

SORBELLO, G. Linee guida per la realizzazione di impianti di maricoltura in Sicilia. Sicilia: Assessorato Territorio Ed Ambiente, Departamento Regionale Territorio e Ambiente, 2008. 63 p.

TOLEDO, A. P. Informe preliminar sobre os estudos para a obtenção de um índice para avaliação do estado trófico de reservatórios de regióes quentes tropicais. São Paulo: CETESB, 1990. 12 p.

VINATEA-ARANA, L. Princípios químicos de qualidade da água em aqüicultura. Florianópolis: Editora da UFSC, 1997. 166 p. 